Article

\title{
Active Compact Wearable Body Area Networks for Wireless Communication, Medical and IoT Applications
}

\author{
Albert Sabban ${ }^{1,2}$ \\ 1 Department of Electrical Engineering, Kinneret College, Kinneret, 15132, Israel; sabban@netvision.net.il; \\ Tel.: +972-4-8759111; Fax: +972-4-8759111 \\ 2 Department of Electrical Engineering, ORT Braude College, Karmiel, 2161002, Israel
}

Received: 21 October 2018; Accepted: 21 November 2018; Published: 23 November 2018

\begin{abstract}
The development of compact wearable antennas and transceivers for communication, IoT (Internet of Things), and biomedical systems will be presented in this paper. Development of Compact efficient wearable antennas is one of the major challenges in development of wearable communication, IoT, and medical systems. The main goal of wireless body area networks (BANs), WBANs, is to provide continuously medical data to the physician. Body area network (BAN) antennas should be flexible, lightweight, compact, and have low production cost. However, low efficiency is the major disadvantage of small printed antennas. Microstrip antennas resonant frequency is altered, due to environment conditions, different antenna locations, and different system operation modes. These disadvantages may be solved by using compact active and tunable antennas. A new class of wideband active wearable antennas for medical applications is presented in this paper. Amplifiers may be connected to the wearable antenna feed line to increase the system dynamic range. Small lightweight batteries supply the bias voltage to the active components. An active dual polarized antenna is presented in this paper. The active dual polarized antenna gain is $14 \pm 3 \mathrm{~dB}$ for frequencies ranging from 380 to $600 \mathrm{MHz}$. The active transmitting dual polarized antenna output power is around $18 \mathrm{dBm}$. A voltage-controlled diode, varactor, may be used to control the antenna electrical performance at different environments. For example, an antenna located in patient stomach area has VSWR (Voltage Standing Wave Ratio) better than 2:1 at $434 \mathrm{MHz}$. However, if the antenna will be placed on the patient back, it may resonate at $420 \mathrm{MHz}$. By varying the varactor bias voltage, the antenna resonant frequency may be shifted from 420 to $434 \mathrm{MHz}$. An ultra-wideband passive and active printed slot antenna may be employed in wideband wearable communication systems. The active slot antenna gain is $13 \pm 2 \mathrm{~dB}$ for frequencies from $800 \mathrm{MHz}$ to $3 \mathrm{GHz}$.
\end{abstract}

Keywords: wearable wireless communication systems; wearable antennas; active antennas; wearable body area networks; medical applications; IoT applications

\section{Introduction}

Wearable systems have several applications in personal communication devices and medical devices, as presented in [1-9]. Printed antennas are frequently used as wearable antennas in BANs and medical systems, see [1-3]. Printed antenna features, such as small volume and low production cost, are crucial in several wireless communication systems. Moreover, printed antennas are compact, flexible, and can be used as wearable antennas. Printed wearable antennas are presented in journals and books, as referred in [10-15]. Investigation of RF transmission near the human body for wearable communication systems is presented in [16-23]. However, small printed antennas suffer from low efficiency [24]. Active antennas for communication systems are presented in journals, as referred 
to in [25-31]. Novel active and tunable wearable antennas for BAN applications is presented in this paper. Active wearable antennas may be used in receiving or transmitting communication and medical systems. In transmitting channels, a power amplifier is connected to the antenna. In receiving channels, a low noise amplifier is connected to the receiving antenna. Amplifiers may be connected to the wearable antenna feed line to increase the system dynamic range. The active loop antenna gain is $25 \pm 2.5 \mathrm{~dB}$ for frequencies ranging from 350 to $580 \mathrm{MHz}$. The active loop antenna noise figure is $0.7 \pm 0.2 \mathrm{~dB}$ for frequencies ranging from 400 to $900 \mathrm{MHz}$. A varactor is used to control the antenna electrical parameters at different locations on the patient body. The antenna resonant frequency may be shifted by $10 \%$ by varying the varactor bias voltage. The presented active antennas electrical performance was optimized by using ADS software [32]. There is good agreement between the computed and measured results in all the active antennas and devices presented in this paper.

\section{Active Wearable Body Area Networks and Antennas}

This paper presents active antennas (AAs) for medical, sports, and IoT applications. Active antennas are devices combining antennas with active components. The radiating element is designed to provide the optimal load to the active elements. The integration of the antenna and the active components drastically reduce the system volume, system weight, and complexity of the matching network. In the last decade, active antennas are employed in wireless and in medical communication systems [25-31]. The major applications of active antennas are electronically scanning arrays and phased arrays. Indeed, arrays of active antennas are well suited for mobile communication systems requiring dynamic satellite tracking. The most common approach toward achieving fast-beam scanning is through the integration of monolithic microwave integrated circuit (MMIC) phase shifters, low noise amplifiers, and solid state power amplifiers with the radiating elements. In some cases, hybrid electromechanical arrays, combining mechanical steering with electrical steering shaping, are used. This architecture is often used to reduce the number of active control elements by limiting the electrical scanning in only one plane. This is often the case for mobile terminals, where azimuth scanning is performed by mechanical rotation, and elevation agility is realized by a linear phased array. Developments in RF technologies, such as MIC, MMIC, LTCC, MEMS, and other fabrication processes allowed automated low-cost production process of phased arrays with a high integration level. Phased arrays are much faster for beam switching than mechanically scanned antennas. Early phased array antennas were passive antennas. The front end of the antenna was composed of array elements with phase shifters. With the great progress of GaAs MMIC technology in the last twenty years, solid state device dimensions have been minimized to the size of the array elements, enabling distributed phased array architectures. High-power amplifiers and low noise amplifiers (LNAs) could be placed close to the front end, and connected to each radiating element. This phased array architecture allows significant power efficiency improvement and better receive sensitivity. The only loss before the first LNA is the antenna. The amplifiers may be packaged in transmit (receive) modules with power dividers (combiners), phase shifters, and attenuators. Development of compact wideband active antennas may improve, significantly, the performance of wearable systems. The design and development of compact printed active loop, dipole, and slot antennas is presented in this paper.

\section{Active Receiving Wearable Body Area Network with Loop Antenna}

Figure 1a presents a basic receiver block diagram with an active antenna. In Figure 1a, the LNA, low noise amplifier, is an integral part of the antenna. A commercial E PHEMT LNA, low noise amplifier, is connected to the printed loop antenna. The loop antenna is etched on an FR4 substrate with a thickness of $0.005 \mathrm{~mm}$. The loop antenna diameter is $50 \mathrm{~mm}$. The active antenna configuration is shown in Figure 1b. The receiving active antenna block diagram is presented in Figure 1c. The radiating element is connected to the LNA via an input matching network. An output matching network connects the amplifier output port to the receiver. A compact DC bias network supplies the required voltages to 
the amplifiers. The amplifier specifications are given in Table 1 . The amplifier complex $\mathrm{S}$ parameters are listed in Table 2. The amplifier noise parameters are listed in Table 2. The amplifier gain is around $25 \mathrm{~dB}$ at $100 \mathrm{MHz}$, and decreases to $8 \mathrm{~dB}$ at $2 \mathrm{GHz}$. The loop antenna S11 parameter on a human body is presented in Figure 1d. A textile sleeve covers the loop antenna to match the loop to the antenna environment. The radiating loop antenna and the textile sleeve are attached to the patient body. The antenna bandwidth, computed and measured, is around 20\% for VSWR; better than 3:1. The active loop antenna S21 parameters, gain, on human body, are shown in Figure 1e. The active antenna gain is $25 \pm 2.5 \mathrm{~dB}$ for frequencies from 350 to $580 \mathrm{MHz}$. The active loop antenna noise figure is $0.7 \pm 0.2 \mathrm{~dB}$ for frequencies from 400 to $900 \mathrm{MHz}$. There is a good agreement between computed and measured.

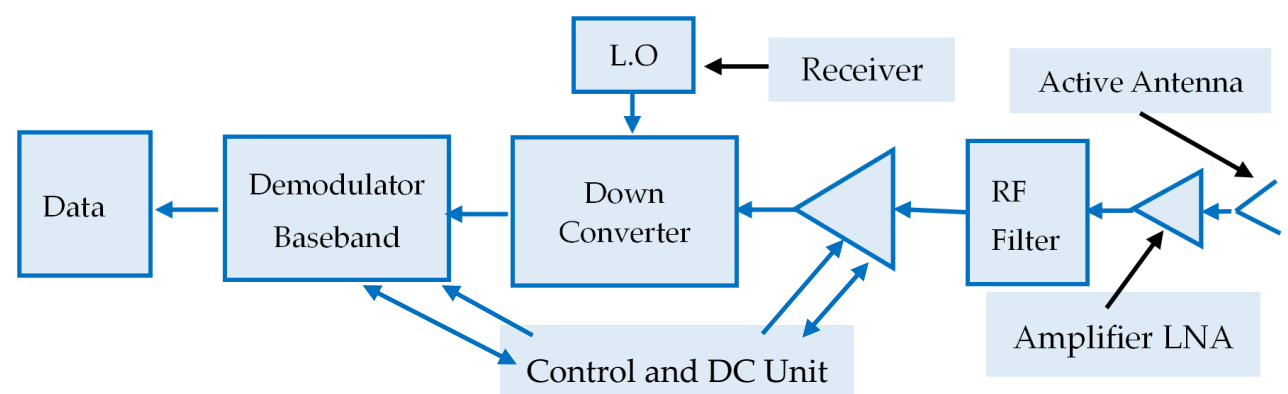

(a)

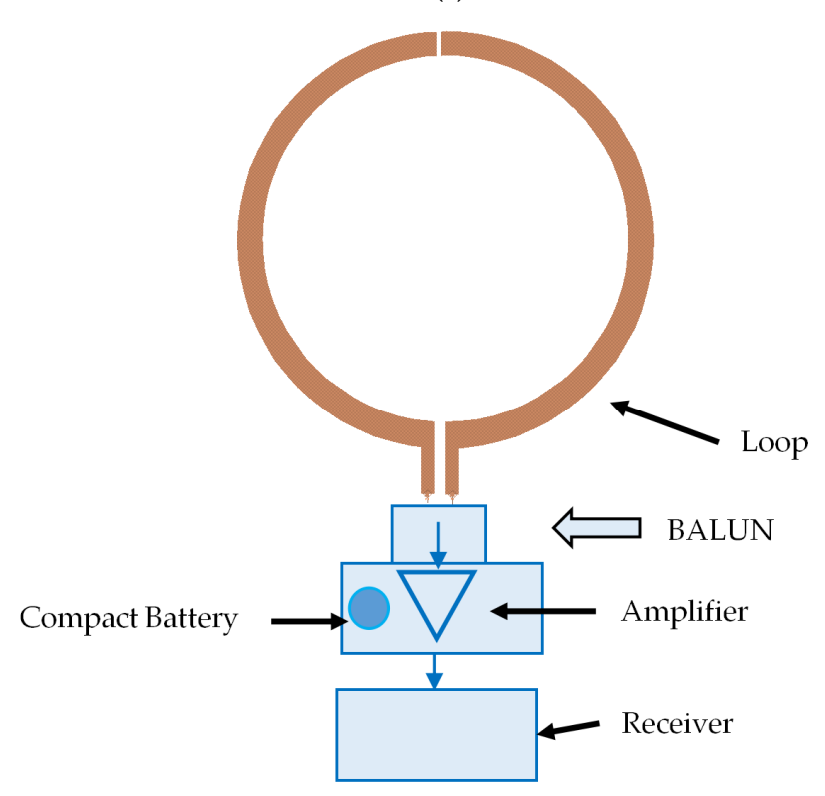

(b)

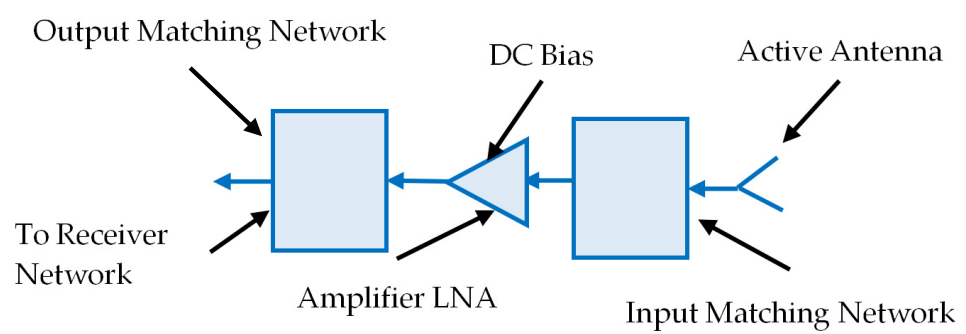

(c)

Figure 1. Cont. 


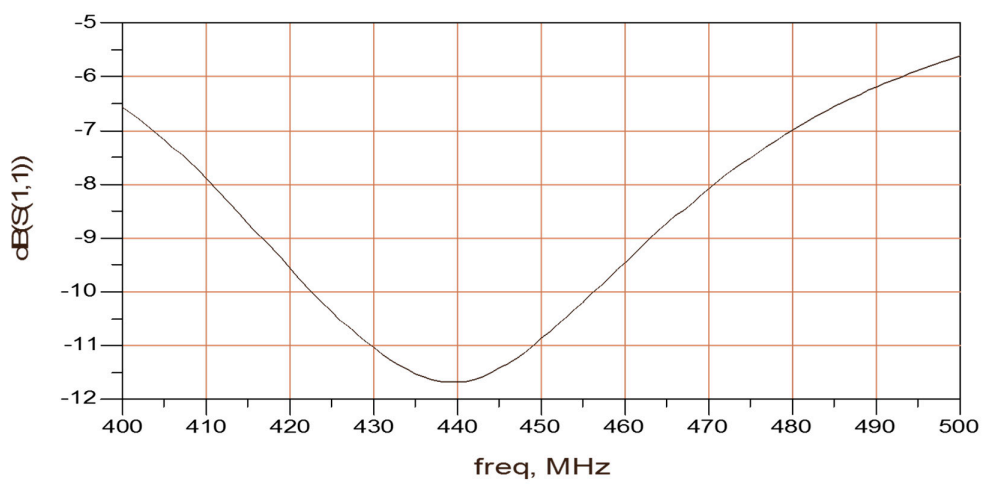

(d)

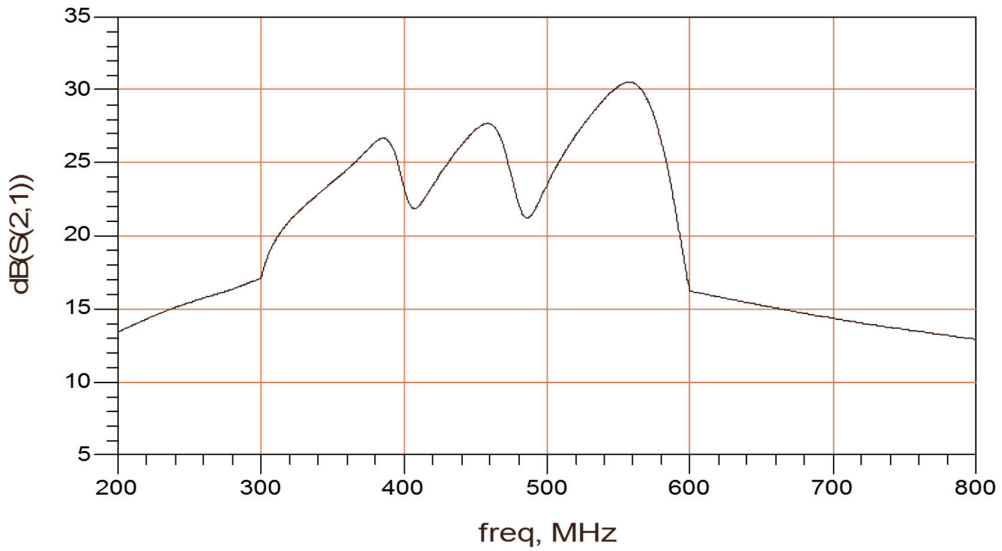

(e)

Figure 1. Receiving active antenna assembly. (a) Receiver block diagram with active antenna; (b) Active printed loop antenna layout; (c) Receiving active antenna block diagram; (d) Loop antenna S11 parameters on human body; (e) Active loop antenna S21 parameter, gain, on human body.

Table 1. Low noise amplifier (LNA) specification.

\begin{tabular}{ccc}
\hline Parameter & Specification & Remarks \\
\hline Frequency range & $0.4-3 \mathrm{GHz}$ & \\
\hline Gain & $\begin{array}{c}26 \mathrm{~dB} @ 0.4 \mathrm{GHz} \\
18 \mathrm{~dB} @ 2 \mathrm{GHz}\end{array}$ & Vds $=3 \mathrm{~V} ; \mathrm{Ids}=60 \mathrm{~mA}$ \\
& $\begin{array}{c}0.4 \mathrm{~dB} @ 0.4 \mathrm{GHz} \\
0.5 \mathrm{~dB} @ 2 \mathrm{GHz}\end{array}$ & Vds $=3 \mathrm{~V} ; \mathrm{Ids}=60 \mathrm{~mA}$ \\
\hline N.F & $\begin{array}{c}18.9 \mathrm{dBm} @ 0.4 \mathrm{GHz} \\
19.1 \mathrm{dBm} @ 2 \mathrm{GHz}\end{array}$ & Vds $=3 \mathrm{~V} ; \mathrm{Ids}=60 \mathrm{~mA}$ \\
\hline P1dB & $32.1 \mathrm{dBm} @ 0.4 \mathrm{GHz}$ & $\mathrm{Vds}=3 \mathrm{~V} ; \mathrm{Ids}=60 \mathrm{~mA}$ \\
\hline OIP3 & $33.6 \mathrm{dBm} @ 2 \mathrm{GHz}$ & \\
\hline Max Input power & $17 \mathrm{dBm}$ & \\
\hline Vgs & $0.48 \mathrm{~V}$ & \\
\hline Vds & $3 \mathrm{~V}$ & \\
\hline Ids & $60 \mathrm{~mA}$ & \\
\hline Supply voltage & $\pm 5 \mathrm{~V}$ & \\
\hline Package & Surface Mount & \\
\hline Operating Temperature & $-40{ }^{\circ} \mathrm{C}-80{ }^{\circ} \mathrm{C}$ & \\
\hline Storage Temperature & $-50{ }^{\circ} \mathrm{C}-8100{ }^{\circ} \mathrm{C}$ & \\
\hline
\end{tabular}


Table 2. LNA S parameters and noise parameters.

\begin{tabular}{|c|c|c|c|c|c|c|c|c|}
\hline F-GHz & S11 & $\mathrm{S}_{11}^{\circ}$ & S21 & $\mathrm{S} 21^{\circ}$ & S12 & $\mathrm{S} 12^{\circ}$ & S22 & $\mathrm{S}_{22}^{\circ}$ \\
\hline 0.10 & 0.986 & -17.17 & 25.43 & 168.9 & 0.008 & 88.22 & 0.55 & -14.38 \\
\hline 0.19 & -31.76 & 0.964 & 24.13 & 158.9 & 0.016 & 74.88 & 0.54 & -22.98 \\
\hline 0.279 & 0.93 & -45.77 & 22.97 & 149.5 & 0.021 & 65.77 & 0.51 & -33.65 \\
\hline 0.323 & 0.92 & -53.39 & 22.45 & 145.3 & 0.026 & 62.38 & 0.49 & -39.2 \\
\hline 0.413 & 0.89 & -65.72 & 20.98 & 137.27 & 0.03 & 57.9 & 0.46 & -49.3 \\
\hline 0.50 & 0.87 & -77.1 & 19.54 & 130.3 & 0.034 & 53.03 & 0.43 & -57.5 \\
\hline 0.59 & 0.83 & -87.12 & 18.08 & 124.14 & 0.038 & 48.18 & 0.40 & -64.12 \\
\hline 0.726 & 0.8 & -100.8 & 16.22 & 115.7 & 0.042 & 42.06 & 0.36 & -74.86 \\
\hline 0.816 & 0.77 & -108.8 & 15.07 & 110.75 & 0.044 & 39.53 & 0.34 & -80.87 \\
\hline 1.04 & 0.74 & -126.2 & 12.74 & 100.13 & 0.049 & 33.69 & 0.29 & -94.96 \\
\hline 1.21 & 0.71 & -137.6 & 11.25 & 92.91 & 0.051 & 30.05 & 0.26 & -104 \\
\hline 1.53 & 0.687 & -154.2 & 9.29 & 82.06 & 0.055 & 26.08 & 0.22 & -119 \\
\hline 1.75 & 0.67 & -164.1 & 8.24 & 75.31 & 0.058 & 23.14 & 0.20 & -128.4 \\
\hline 2.02 & 0.67 & -174.6 & 7.27 & 67.82 & 0.06 & 20.88 & 0.18 & -138.8 \\
\hline \multicolumn{9}{|c|}{ Noise Parameters } \\
\hline \multicolumn{2}{|c|}{ F-GHz } & \multicolumn{2}{|c|}{ N.FMIN } & \multicolumn{2}{|c|}{ N11X } & \multicolumn{2}{|c|}{ N11Y } & rn \\
\hline \multicolumn{2}{|c|}{0.5} & \multicolumn{2}{|c|}{0.079} & \multicolumn{2}{|c|}{0.3284} & \multicolumn{2}{|c|}{24.56} & 0.056 \\
\hline \multicolumn{2}{|c|}{0.7} & \multicolumn{2}{|c|}{0.112} & \multicolumn{2}{|c|}{0.334} & \multicolumn{2}{|c|}{36.08} & 0.05 \\
\hline \multicolumn{2}{|c|}{0.9} & \multicolumn{2}{|c|}{0.144} & \multicolumn{2}{|c|}{0.3396} & \multicolumn{2}{|c|}{47.4} & 0.045 \\
\hline \multicolumn{2}{|c|}{1} & \multicolumn{2}{|c|}{0.16} & \multicolumn{2}{|c|}{0.3424} & \multicolumn{2}{|c|}{52.98} & 0.042 \\
\hline \multicolumn{2}{|c|}{1.9} & \multicolumn{2}{|c|}{0.306} & \multicolumn{2}{|c|}{0.3682} & \multicolumn{2}{|c|}{100.93} & 0.029 \\
\hline \multicolumn{2}{|c|}{2} & \multicolumn{2}{|c|}{0.322} & \multicolumn{2}{|c|}{0.3711} & \multicolumn{2}{|c|}{106.01} & 0.029 \\
\hline \multicolumn{2}{|c|}{2.4} & 0.3 & & & & & & 0.029 \\
\hline & & 0.4 & & & & & & 0.036 \\
\hline & & 0.6 & & & & & & 0.059 \\
\hline & & 0.8 & & & & & & 0.11 \\
\hline & & 0.9 & & & & & & 0.162 \\
\hline & & 0.5 & & & & & & 0.177 \\
\hline
\end{tabular}

\section{Active Receiving Wearable Body Area Network with a Dual Polarized Antenna}

A compact dual polarized antenna is shown in Figure 2a, and the antenna was presented in [4]. The antenna feed network is printed on a $0.25 \mathrm{~mm}$-thick FR4 dielectric substrate. The radiating element is printed on a second layer, which is a $0.25 \mathrm{~mm}$-thick Kapton substrate. The antenna thickness is $0.005 \mathrm{~mm}$. The antenna size is $50 \times 50 \mathrm{~mm}$. A compact dual polarized active receiving radiating element is shown in Figure $2 b$. The compact dual polarized antenna may be attached to the patient body. The antenna bandwidth is around $12 \%$ for VSWR, better than 2:1. The active dual polarized antenna S21 parameter, gain, on human body, is shown in Figure 2c. The active antenna gain is $25 \pm 2.5 \mathrm{~dB}$ for frequencies ranging from 380 to $680 \mathrm{MHz}$. The active loop antenna noise figure is $1 \pm 0.5 \mathrm{~dB}$ for frequencies ranging from 400 to $900 \mathrm{MHz}$, as shown in Figure 2d. 


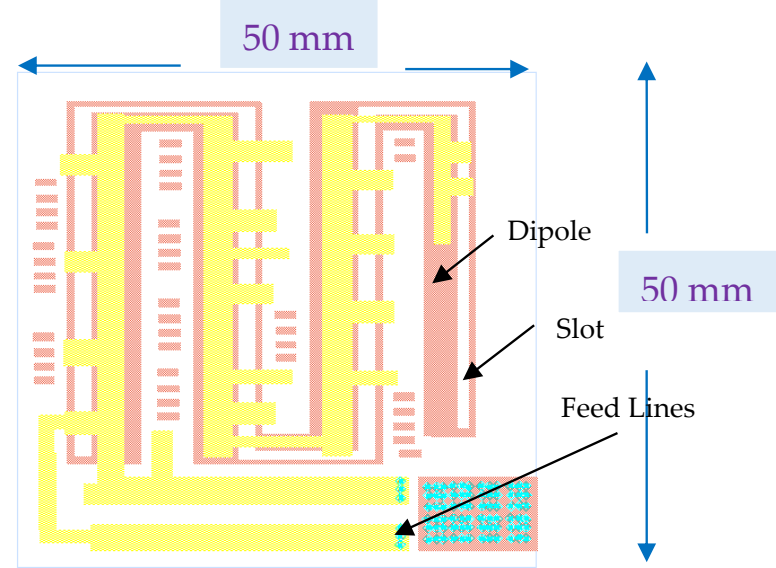

(a)

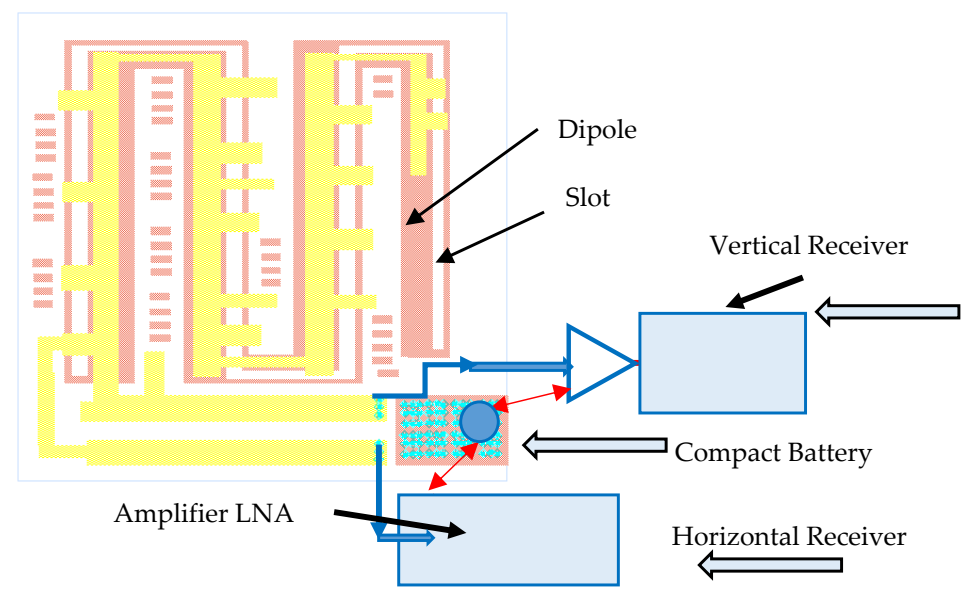

(b)

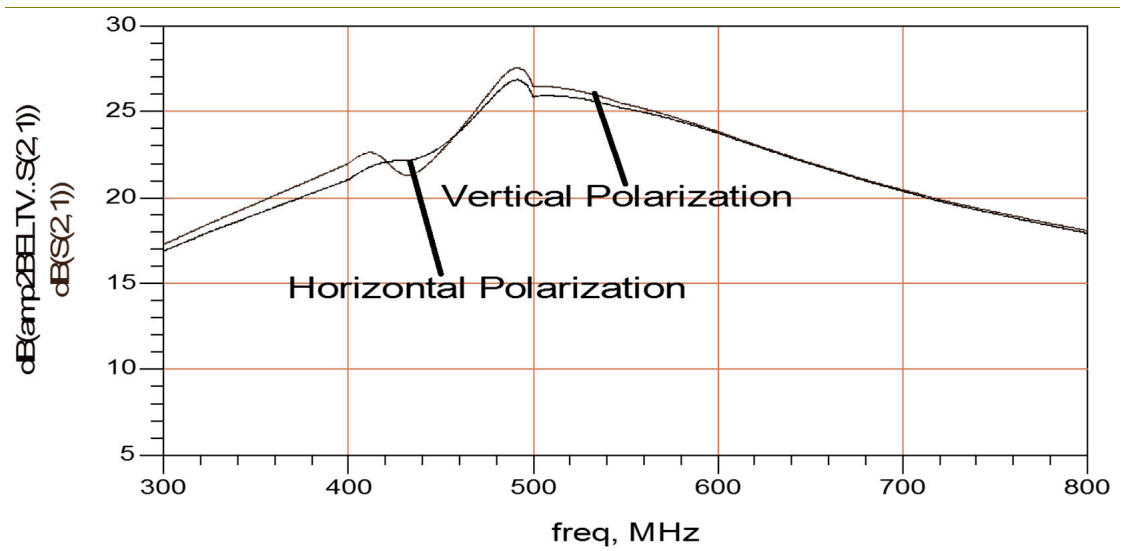

(c)

Figure 2. Cont. 


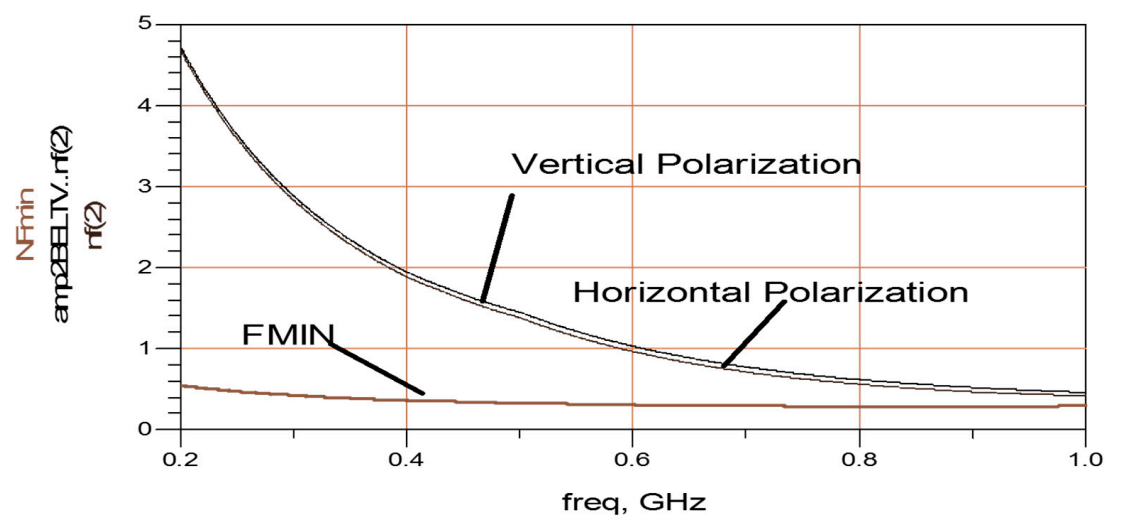

(d)

Figure 2. (a) Printed compact dual polarized wearable antenna; (b) Active printed compact dual polarized receiving antenna layout; (c) Active dual polarize antenna S21 parameter, gain, on human body; (d) Active dual polarize receiving antenna noise figure.

\section{Active Transmitting Wearable Body Area Network with a Dual Polarized Antenna}

Figure 3a presents a basic transmitter block diagram with an active antenna. A printed compact dual polarized transmitting antenna is presented in Figure $3 \mathrm{~b}$. The antenna volume is $50 \mathrm{~mm} \times 50 \mathrm{~mm} \times 0.005 \mathrm{~mm}$. In Figure 3b, the high-power amplifier, HPA, is an integral part of the antenna. The HPA, a MMIC GaAs MESFET, is connected to the transmitting antenna. The active transmitting dual polarized antenna layout is shown in Figure $3 \mathrm{~b}$. The amplifier pin description is shown in Figure $3 \mathrm{~b}$. The transmitting active antenna block diagram is presented in Figure 3c. The radiating element is connected to the HPA via an output HPA matching network. The HPA input matching network connects the amplifier port to the transmitter. The amplifier specifications are given in Table 3. The high-power amplifier complex $\mathrm{S}$ parameters are listed in Table 4 . The active transmitting dual polarized antenna S11 parameters, computed and measured, is better than 3:1 in the frequency range from 410 to $450 \mathrm{MHz}$. The active transmitting dual polarized antenna S21 parameter, gain, on human body is presented in Figure 3d. The active dual polarized antenna gain, computed and measured, is $14 \pm 3 \mathrm{~dB}$ for frequencies ranging from 380 to $600 \mathrm{MHz}$. The active transmitting dual polarized antenna output power is around $18 \mathrm{dBm}$.

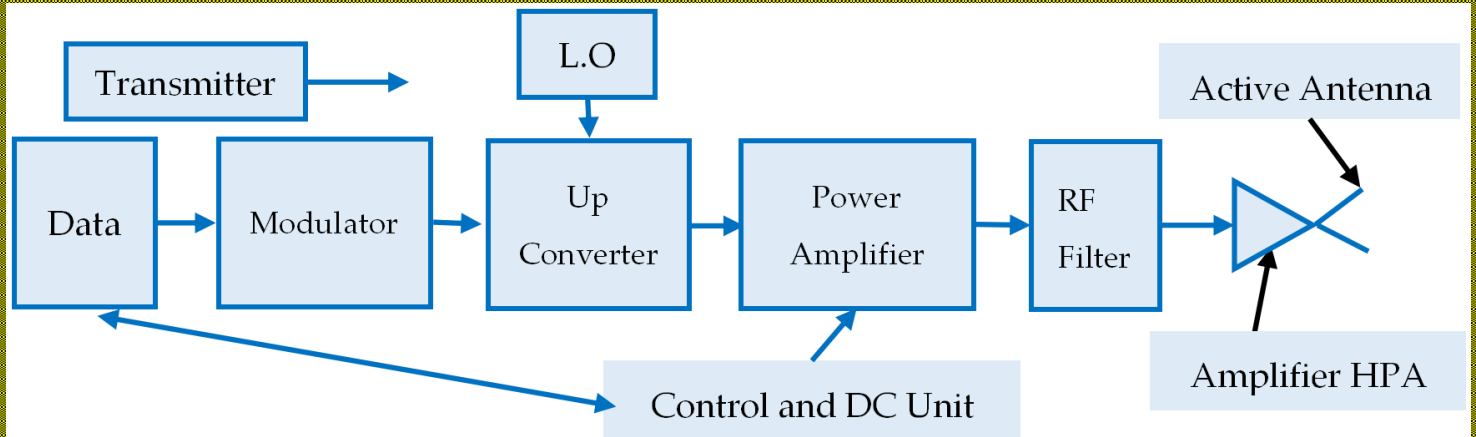

(a)

Figure 3. Cont. 


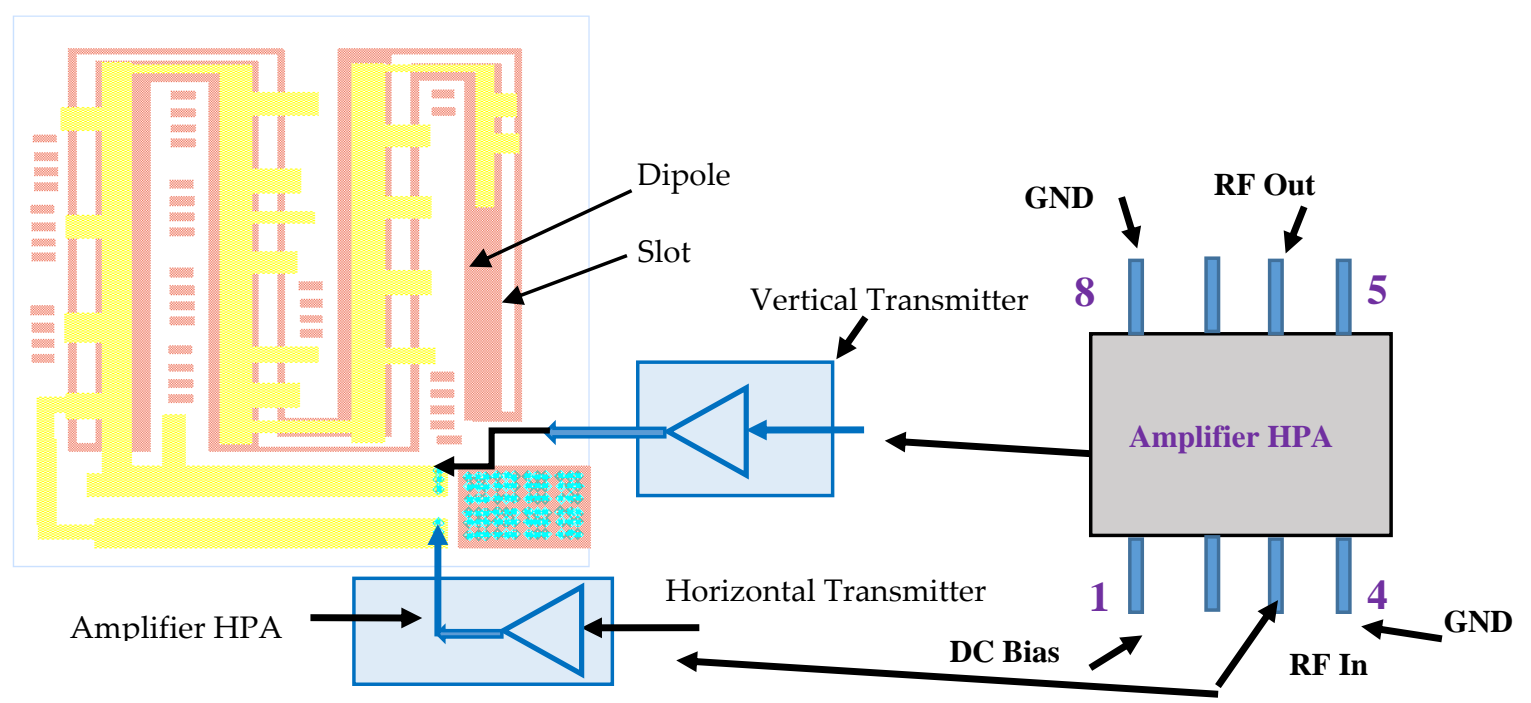

(b)

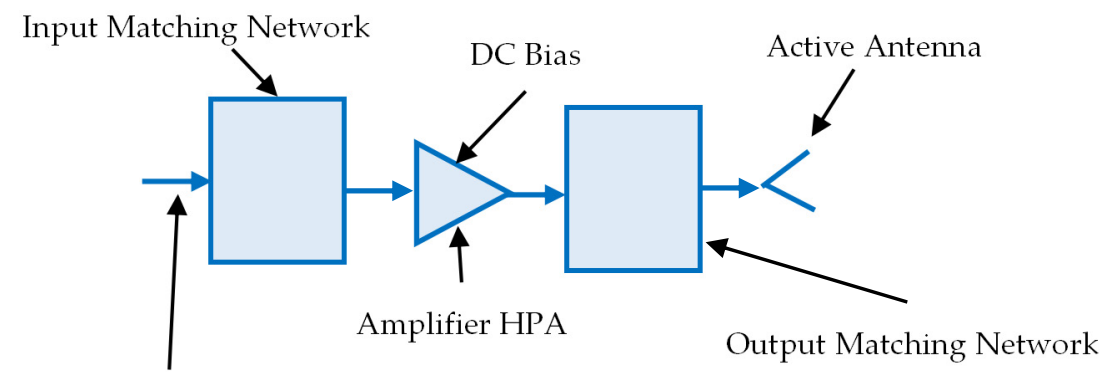

To Transmitter Network

(c)

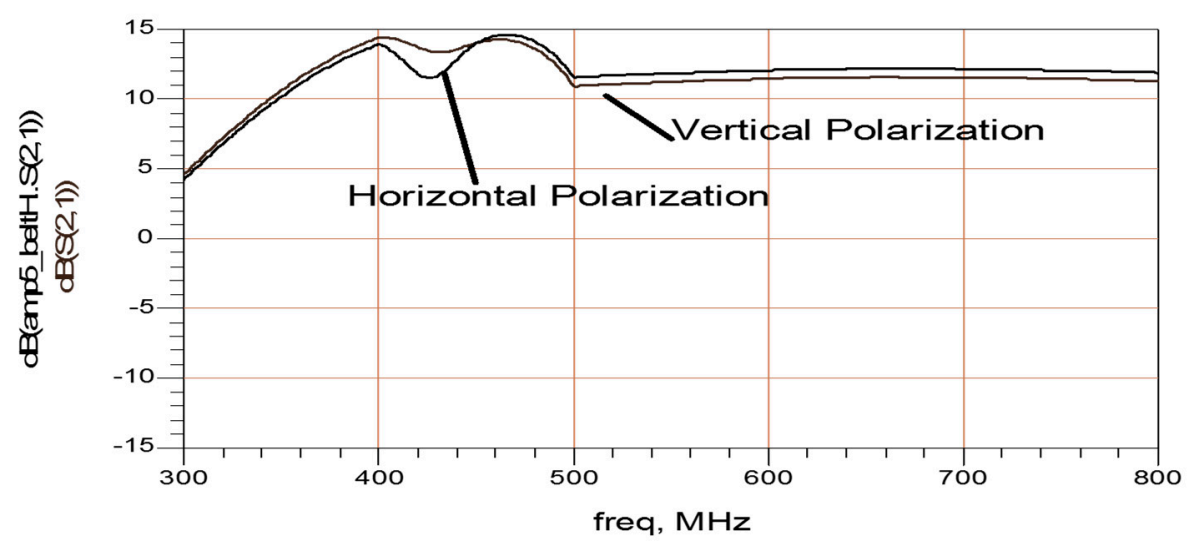

(d)

Figure 3. (a) Transmitter block diagram with active transmitting antenna; (b) Transmitting active compact dual polarized antenna layout; (c) Transmitting active antenna block diagram; (d) Active dual polarized antenna S21 parameter, gain, on human body.

An active transmitting loop antenna layout and block diagram is shown in Figure 4a. The radiating element is connected to the HPA via the HPA output matching network. The HPA input matching network connects the amplifier input port to the transmitter. The amplifier specifications are listed in Table 3. The HPA complex S parameters are listed in Table 4. The active transmitting loop antenna S21 
parameters, gain, on a patient, are presented in Figure $4 \mathrm{~b}$. The active transmitting loop antenna S11 and S22 parameters on human body are better than 3:1 in the frequency range from 360 to $600 \mathrm{MHz}$. The active dual polarized antenna gain is $13 \pm 3 \mathrm{~dB}$ for frequencies from 360 to $600 \mathrm{MHz}$. The active transmitting dual polarized antenna output power is around $18 \mathrm{dBm}$. There is a good agreement between computed and measured values.

Table 3. High-power amplifier (HPA) specification.

\begin{tabular}{ccc}
\hline Parameter & Specification & Remarks \\
\hline Frequency range & $0.4-2.5 \mathrm{GHz}$ & \\
\hline Gain & $15 \mathrm{~dB} @ 0.4 \mathrm{GHz}$ & Vds $=5 \mathrm{~V} ; \mathrm{Ids}=85 \mathrm{~mA}$ \\
& $17.8 \mathrm{~dB} @ 2 \mathrm{GHz}$ & \\
\hline N.F & $\begin{array}{c}5.5 \mathrm{~dB} @ 0.4 \mathrm{GHz} \\
5.5 \mathrm{~dB} @ 2 \mathrm{GHz}\end{array}$ & Vds $=5 \mathrm{~V} ; \mathrm{Ids}=85 \mathrm{~mA}$ \\
\hline P1dB & $18.0 \mathrm{dBm} @ 0.4 \mathrm{GHz}$ & $\mathrm{Vds}=5 \mathrm{~V} ; \mathrm{Ids}=85 \mathrm{~mA}$ \\
\hline OIP3 & $18.0 \mathrm{dBm} @ 2 \mathrm{GHz}$ & \\
\hline & $29 \mathrm{dBm} @ 0.4 \mathrm{GHz}$ & $\mathrm{Vds}=5 \mathrm{~V} ; \mathrm{Ids}=85 \mathrm{~mA}$ \\
\hline Max. Input power & $29 \mathrm{dBm} @ 2 \mathrm{GHz}$ & \\
\hline Vgs & $10 \mathrm{dBm}$ & \\
\hline Vds & $0.48 \mathrm{~V}$ & $\mathrm{Vds}=5 \mathrm{~V} ; \mathrm{Ids}=85 \mathrm{~mA}$ \\
\hline Ids & $5 \mathrm{~V}$ & \\
\hline Supply voltage & $85 \mathrm{~mA}$ & \\
\hline Package & $\pm 5 \mathrm{~V}$ & \\
\hline Operating Temperature & $-40{ }^{\circ} \mathrm{C}-80{ }^{\circ} \mathrm{C}$ & \\
\hline Storage Temperature & $-50{ }^{\circ} \mathrm{C}-100{ }^{\circ} \mathrm{C}$ & \\
\hline
\end{tabular}

Table 4. High-power amplifier S parameters.

\begin{tabular}{ccccccccc}
\hline F-GHz & S11 dB & S11 $^{\circ}$ & S21 dB & S21 $^{\circ}$ & S12 dB & S12 $^{\circ}$ & S22 dB & S22 $^{\circ}$ \\
\hline 0.20 & 0.065 & -38.75 & -3.09 & -139.2 & -47.56 & 157.63 & -1.03 & -74.66 \\
0.344 & -1.1 & -77 & 11.8 & 118.7 & -37.9 & 78.4 & -7.2 & -131.6 \\
0.4 & -2.2 & -88.5 & 13.8 & 85.24 & -36.9 & 52.76 & -11 & -143.5 \\
0.52 & -4.44 & -107.5 & 15.8 & 30.2 & -36.7 & 14.1 & -19.4 & -132.5 \\
0.64 & -6.4 & -122 & 16.8 & -11.4 & -37.2 & -12.6 & -19.2 & -100.3 \\
0.712 & -7.4 & -100.8 & 17.13 & -32.7 & -37.5 & -25.4 & -17.7 & -100.6 \\
0.88 & -9.2 & -144.6 & 17.72 & -77.1 & -38.5 & -49.4 & -15.7 & -119.7 \\
1.04 & -10.4 & -158.6 & 18.1 & -115.1 & -39.6 & -67.5 & -15.3 & -144.5 \\
1.24 & -11.3 & -178.7 & 18.37 & -159.7 & -41.3 & -86.9 & -15.9 & -178.7 \\
1.36 & -11.8 & 167.4 & 18.4 & 174.4 & -42.4 & -91.4 & -16.5 & 159.2 \\
1.48 & -12.2 & 151.2 & 18.4 & 149 & -43.6 & -94.9 & -17.5 & 136.8 \\
1.6 & -12.8 & 134.3 & 18.3 & 123.3 & -44.2 & -93.4 & -18.9 & 113.7 \\
1.8 & -14.3 & 101.2 & 17.9 & 83 & -43 & -86.3 & -22 & 69.5 \\
2 & -16.5 & 61.8 & 17.3 & 43.5 & -40.4 & 94.6 & -27 & 6.42 \\
2.16 & -18.5 & 22.1 & 16.8 & 12.9 & -38 & -105.5 & -27.8 & -70.2 \\
2.4 & -19.4 & -53.9 & 15.7 & -31.8 & -36 & -128 & -22.2 & -147.2 \\
2.56 & -17.7 & 99.7 & 15 & -60 & -34.6 & -145.6 & -19.3 & -179.4 \\
2.7 & -15.7 & 131 & 14.3 & -84.3 & -33.8 & -160.3 & -17.5 & 158.1 \\
2.86 & -13.7 & 159 & 13.5 & -111.1 & -33 & -177.7 & -16 & 134.7 \\
3 & -12.2 & 179.1 & 12.7 & -134.1 & -32.4 & 167.4 & 15.2 & 116.3 \\
\hline
\end{tabular}




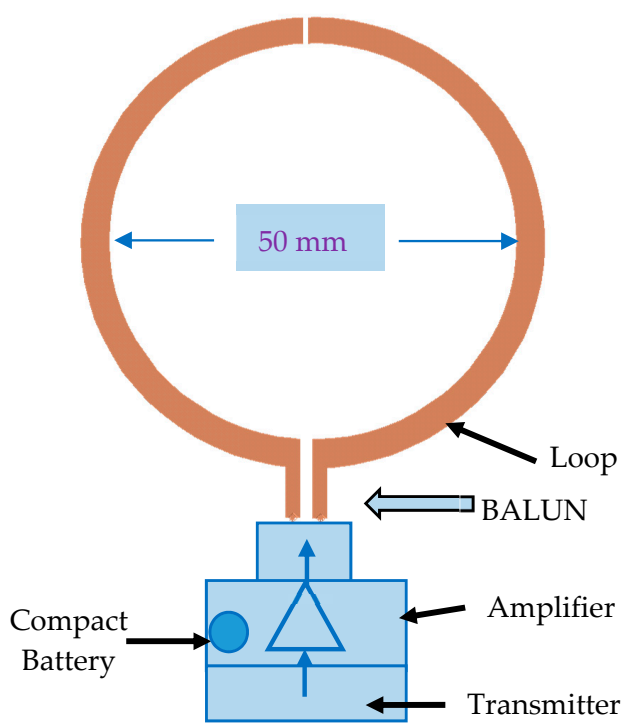

(a)

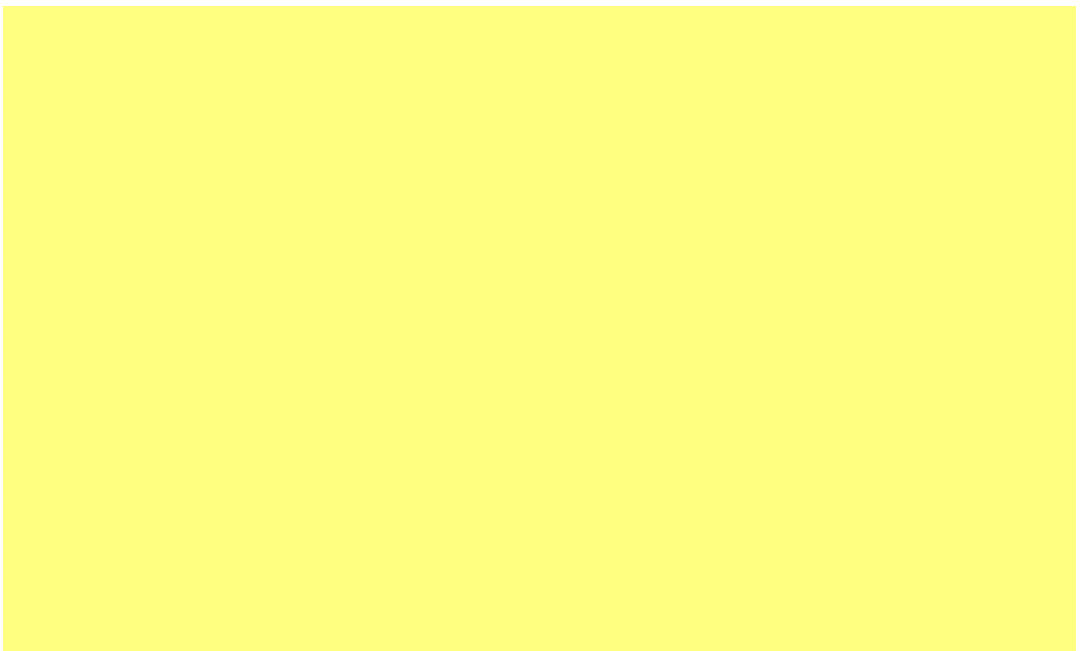

(b)

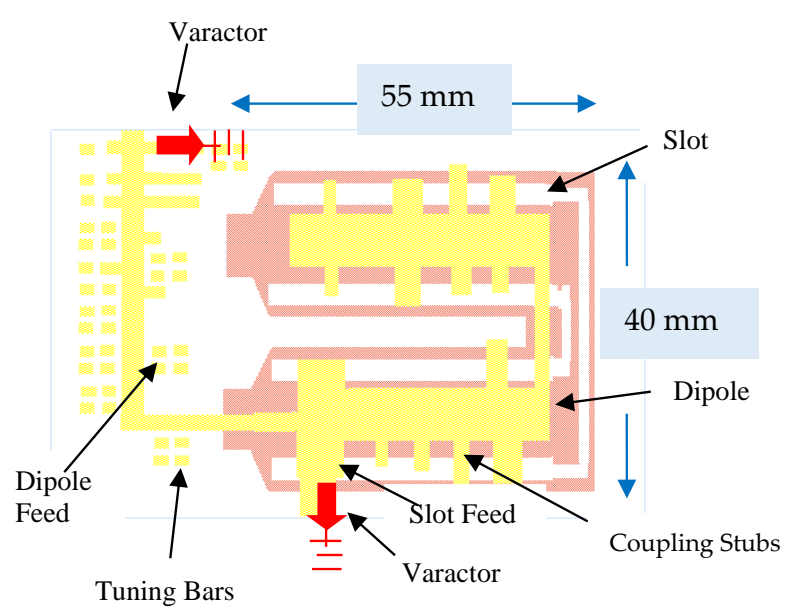

(c)

Figure 4. Cont. 


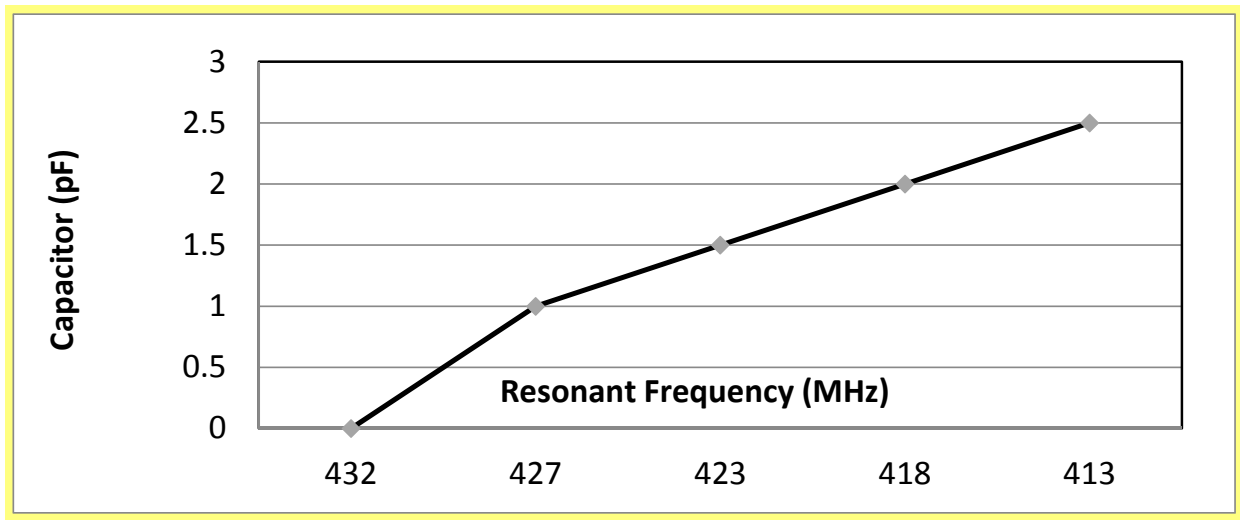

(d)

Figure 4. (a) Active transmitting printed loop antenna layout; (b) Active transmitting loop antenna S21 parameter; (c) Tunable folded compact dual polarized antenna; (d) Resonant frequency of a tunable antenna as function of varactor capacitance.

\section{Tunable Wearable Body Area Network}

Small printed tunable antennas are crucial in the development of Wearable BAN, WBAN, systems. Tunable antennas consist of a radiating element and of a voltage-controlled diode, varactor. Varactor diodes are used in voltage-controlled oscillators, VCOs. Varactor diodes are semiconductor devices that are used in many microwave systems where a voltage-controlled variable capacitance is required. Varactor diodes function as a voltage-controlled variable capacitance. The radiating element may be a microstrip patch antenna, dipole, or loop antenna. The antenna resonant frequency may be adjusted by using a voltage-controlled diode to tune variations in the antenna resonant frequency at different environments. The varactor capacitance is given in Equation (1). The circuit frequency, $f_{r}$, may be calculated by using Equation (2).

$$
C=\frac{A \varepsilon}{d}
$$

where $C$-capacitance, $A$-plate area, and $d$ —diode thickness.

$$
f_{r}=\frac{1}{2 \pi \sqrt{L C}}
$$

Varactors are voltage-controlled diodes used to tune microwave devices. Low frequency varactors are manufactured on silicon substrates. High frequency varactors are manufactured on gallium arsenide substrate. Gallium arsenide diodes have higher $Q$ values, in comparison to silicon diodes. Hyper-abrupt voltage-controlled diodes have nearly linear frequency variation as a function of the applied bias voltage. Abrupt varactors have inverse fourth root frequency variation as a function of the applied controlled voltage. For example, a varactor with $20 \mathrm{pF}$ capacitance may tune a small wearable loop antenna to $433 \mathrm{MHz}$.

A folded printed tunable antenna is presented in Figure 4c. The antenna volume is $70 \mathrm{~mm} \times 50 \mathrm{~mm} \times 0.016 \mathrm{~mm}$. The folded dipole has a horizontal polarization. The folded slot antenna is vertically polarized. The combined tunable antenna has dual orthogonal polarizations. The antenna is printed on two dielectric substrates. The antenna feed network is printed on a RO3035 substrate that is $0.8 \mathrm{~mm}$ thick. The folded antenna is printed on a substrate with 2.2 dielectric constant that is $0.8 \mathrm{~mm}$ thick. The location and size of the coupling stubs, shown in Figure 4c, are optimized to achieve the best antenna VSWR. The antenna electrical performance was optimized by using ADS software [32]. The antenna resonant frequency may be tuned by connecting the small tuning bars located along the feed line to the antenna feed line. Varactors are connected to the antenna feed lines, as shown in Figure 4c, to tune the antenna resonant frequency. The varactor control voltage may be 
varied automatically to tune the antenna center frequency at different locations on the patient body The antenna bandwidth is better than $10 \%$ for VSWR better than 2:1. The printed tunable antenna beam width is around $100^{\circ}$. The tunable antenna resonant frequency as a function of the varactor capacitance for capacitances up to $2.5 \mathrm{pF}$ is presented in Figure $4 \mathrm{~d}$. The antenna resonant frequency varies around $\pm 5 \%$ for capacitances up to $2.5 \mathrm{pF}$. The antenna gain may vary between 1 to $3 \mathrm{~dB}$ as a function of the antenna environment. Photos of small printed tunable antennas for WBAN applications are shown in Figure $5 \mathrm{a}$. Figure $5 \mathrm{~b}$ presents a photo of small dual polarized tunable antenna with a varactor connected to the antenna feed line. The varactor bias voltage was varied from 0 to $9 \mathrm{~V}$. Figure $5 c$ presents measured $S_{11}$ as function of varactor bias voltage. The antenna resonant frequency was shifted by $5 \%$ for bias voltage between 7 and $9 \mathrm{~V}$. A voltage-controlled varactor may be used also to tune the loop antenna resonant frequency at different antenna locations on the body. We may conclude that varactors may be used to compensate variations in the antenna resonant frequency at different locations on the human body.

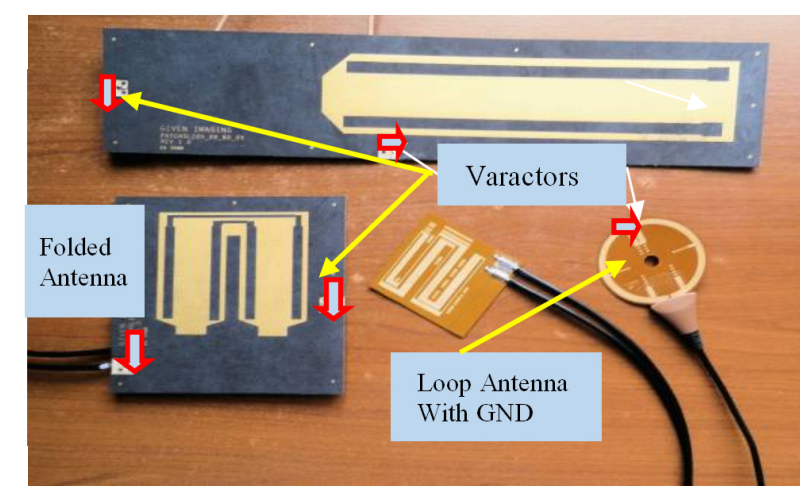

(a)

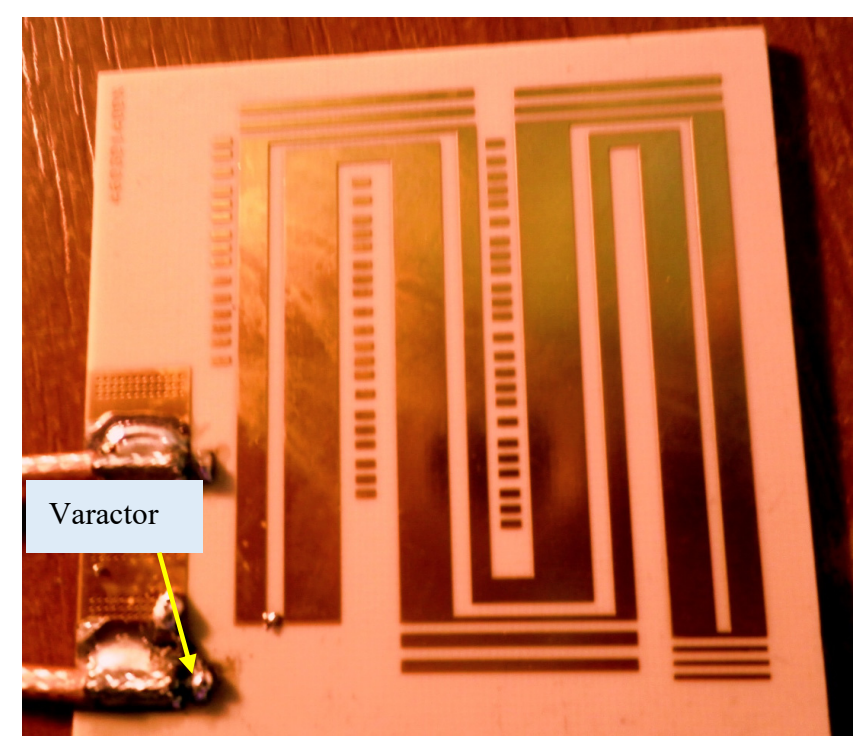

(b)

Figure 5. Cont. 


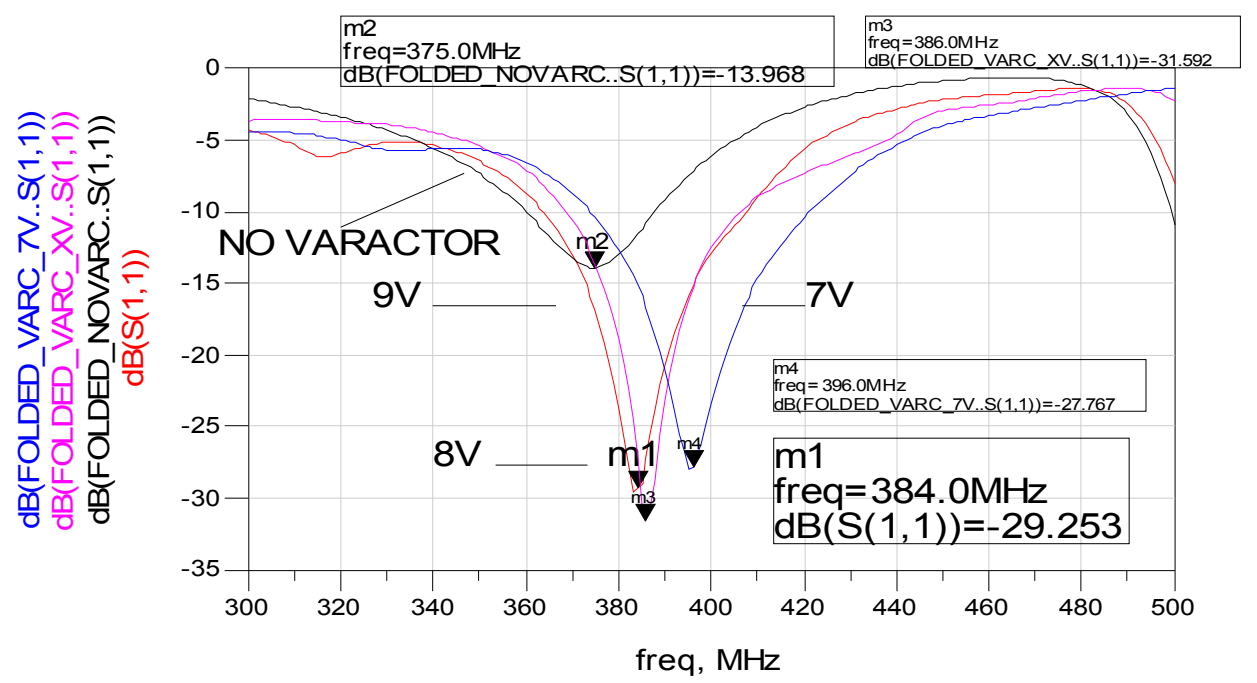

(c)

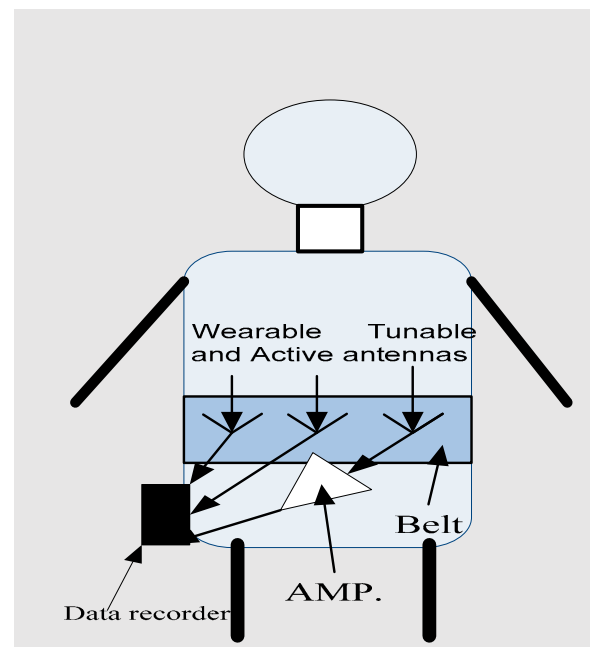

(d)

Figure 5. (a) Tunable wearable antennas for medical applications; (b) Photo of tunable compact wearable antenna with a varactor; (c) Measured $\mathrm{S}_{11}$ of a tunable antenna as function of varactor bias voltage; (d) Active and tunable wearable antenna.

\section{Medical Applications for Tunable Wearable Body Area Network}

Three to four active compact antennas or active loop antennas may be assembled in a belt and attached to the patient stomach or back, as shown in Figure $5 \mathrm{~d}$. The bias voltage to the active elements is supplied by a compact recorder battery. The RF and DC cables from each radiator are connected to a recorder. The recorder consists of a switching matrix, low noise amplifier, filters, and a signal processing unit. The antennas receive signals that are transmitted from sensors that are located on the patient body. During the medical test, the signals are transferred to the signal processing unit. During the system operation, the varactors bias voltage may be varied automatically to tune the medical device to the desired system frequency. Active and tunable antennas may be placed on the patient body in several locations to improve the level of the received signal. The proposed active antennas may be placed on the human body, as shown in Figure 6a. The patient in Figure $6 \mathrm{~b}$ is wearing a wearable antenna that are placed inside a belt. The antennas belt may be attached to the patient stomach or back. 


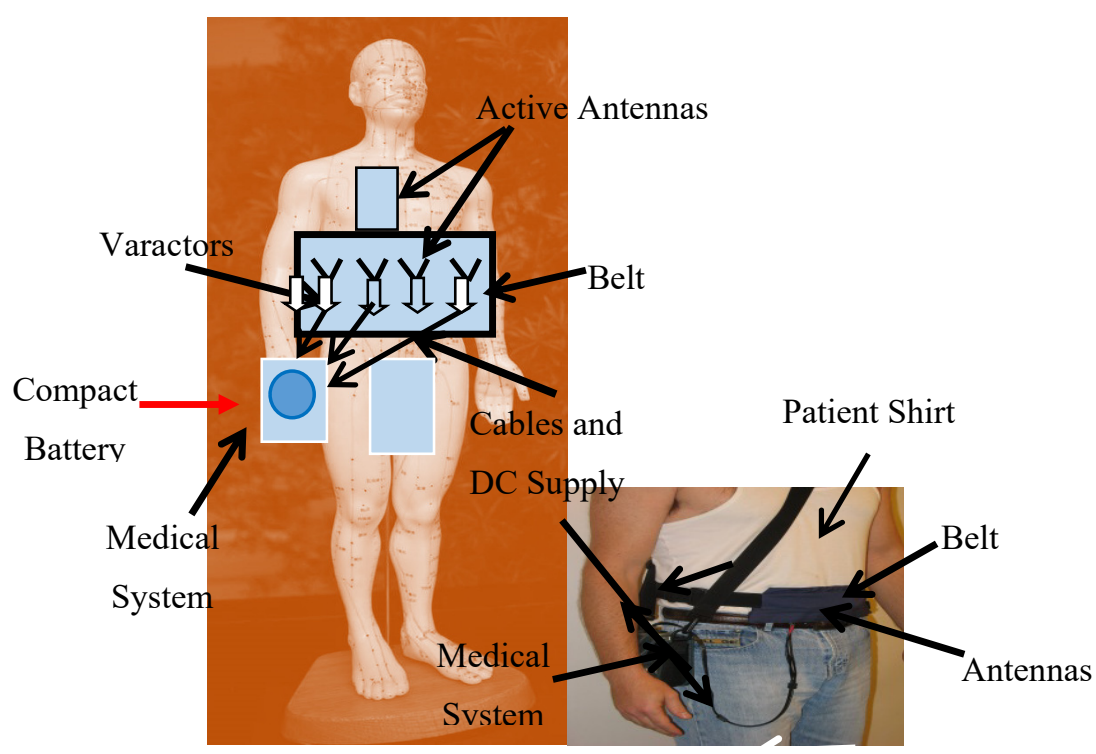

(a)

(b)

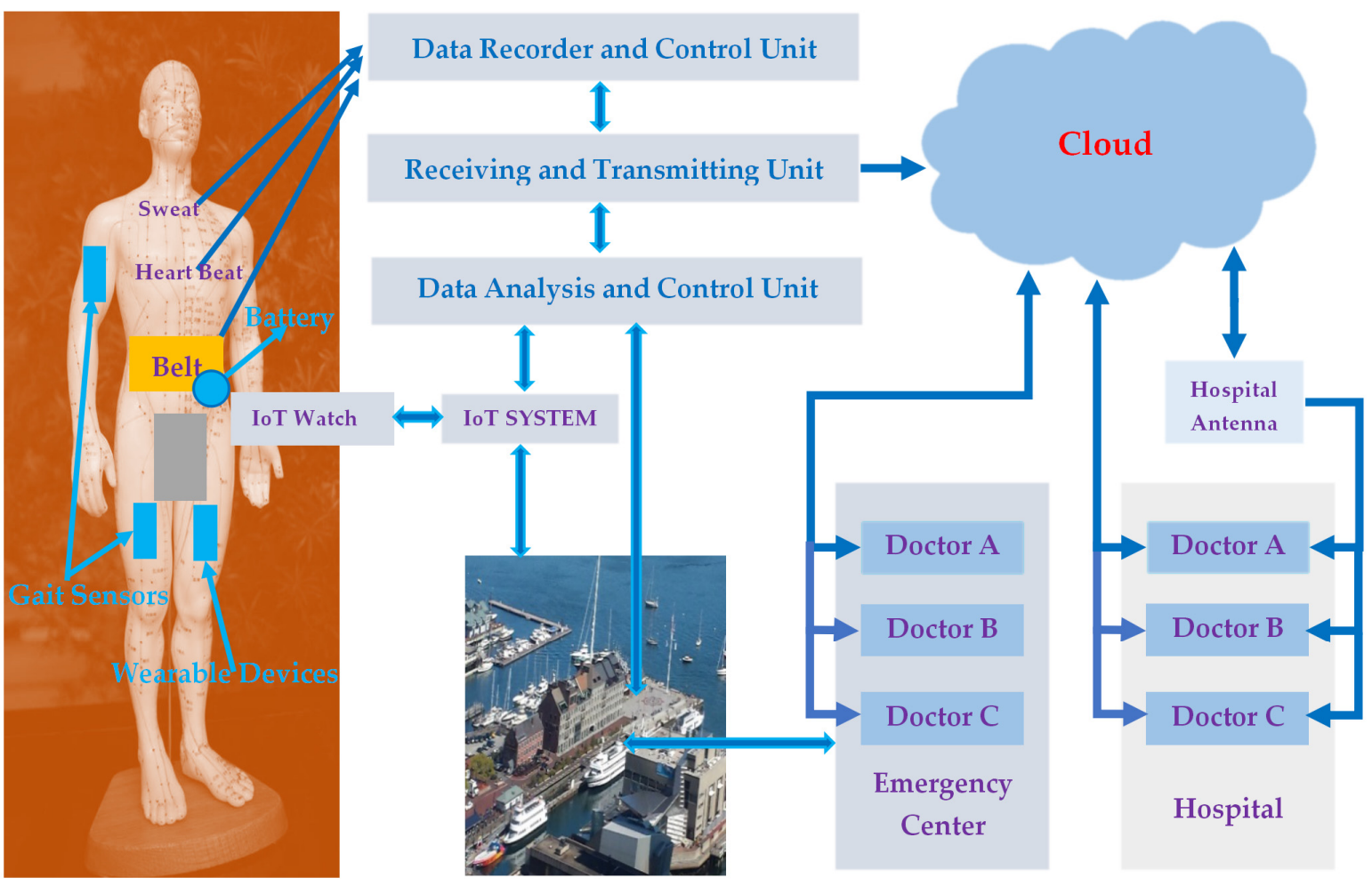

(c)

Figure 6. Cont. 


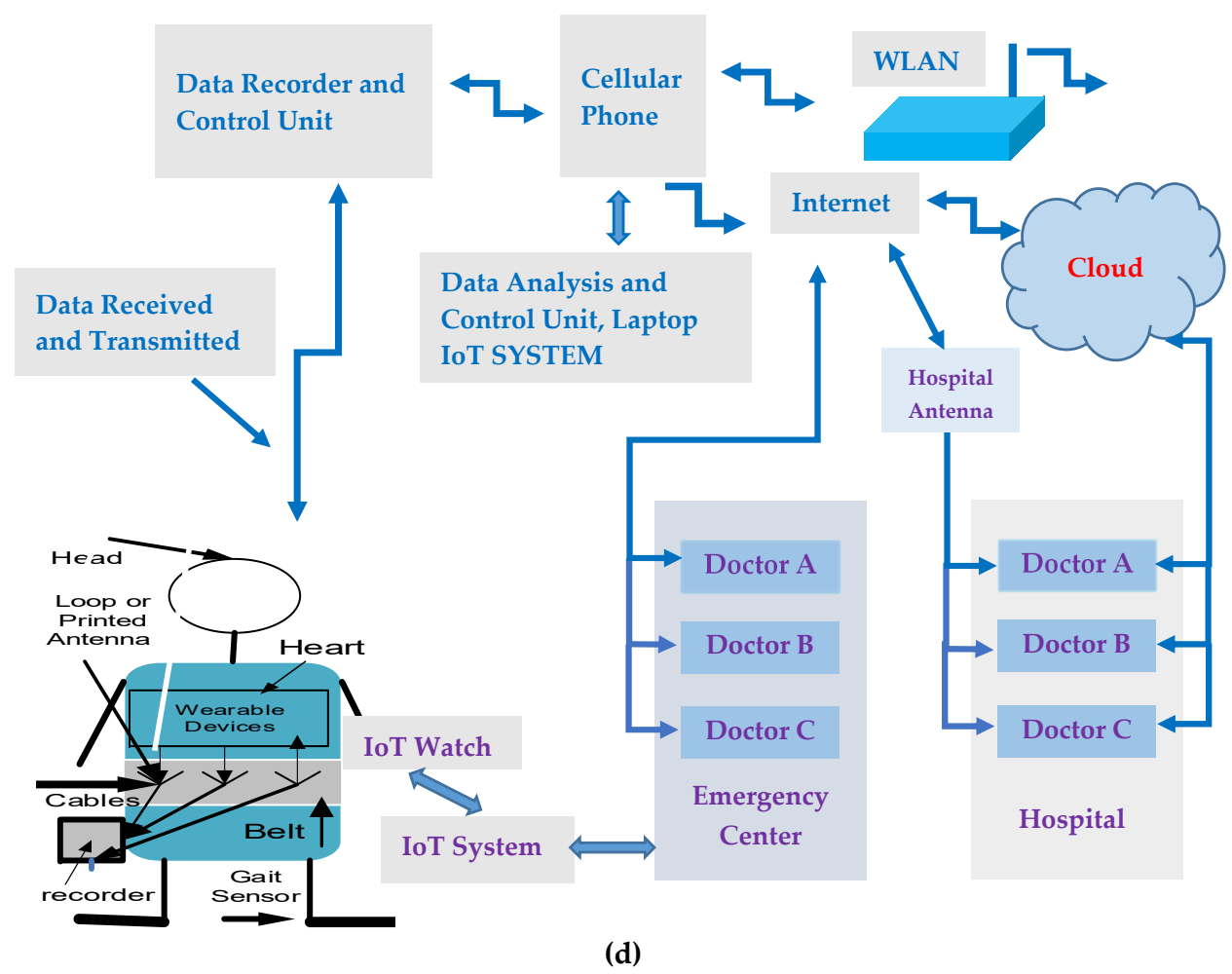

Figure 6. (a) Medical system with printed wearable antennas; (b) Patient with printed wearable antenna; (c) IoT wearable body area network (WBAN) health monitoring system; (d) IoT wireless wearable body area network (WBAN) health monitoring system.

\section{Wireless Body Area Networks (WBANs) and Wearable (WBANs)}

A wearable body area network (WBAN) health monitoring system is presented in Figure 6c. A typical wireless body area network consists of several compact low-power sensing devices, a control unit, and wireless transceivers, as shown in Figure 6c. The power supply for these components should be compact, lightweight, and long-lasting as well. The recorded and monitoring data may be stored and analyzed by employing cloud storage and cloud computing services. Moreover, IoT technology may be used to transmit and receive from person to medical centers, and from medical stuff to patient. Wireless communication systems offer a wide range of benefits to medical centers, patients, physicians, and sport centers, through continuous measuring and monitoring medical information, early detection of abnormal conditions, supervised rehabilitation, and potential discovery of knowledge through data analysis of the collected information. Wearable health monitoring systems, as shown in Figure 6c, allow the person to closely follow changes in important health parameters, and provide feedback for maintaining optimal health status at every location in the world. The main goal of WBANs is to continuously provide biofeedback data. WBANs can record electrocardiograms, measure body temperature and blood pressure, measure heartbeat rate, arterial blood pressure, electro-dermal activity, and other healthcare parameters in an efficient way. For example, accelerometers can be used to sense heartbeat rate, movement, or even muscular activity. Body area networks (BANs) include the applications and communication devices using wearable and implantable wireless networks. A sensor network that senses health parameters is called a body sensor network (BSN). A wireless body area network (WBAN) is a special purpose wireless sensor network that incorporates different networks and wireless devices to enable remote monitoring in various environments.

In medical centers, where conditions of a large number of patients are constantly being monitored, a WBAN system may be extremely needed. A wireless wearable body area network (WBAN) health monitoring system is presented in Figure 6d. 
Wireless monitoring of physiological signals of a large number of patients is needed in order to deploy a complete WSN in hospitals. Human health monitoring is emerging as a crucial application of the embedded sensor networks. A WBAN can monitor vital signs, providing real-time feedback to allow many patient diagnostics procedures using continuous monitoring of chronic conditions, or progress of recovery from an illness. The progress in wireless networking technology promises a new class of wireless sensor networks suitable for WBAN systems.

Data acquisition in WBAN devices can be point-to-point or multipoint-to-point, depending on specific applications. Detection of an athlete's health condition would require point-to-point data sharing across various on-body sensors. Human body monitoring of vital signs will require routing data from several wearable sensors, multipoint-to-point, to a sink node, which, in turn, can relay the information wirelessly to an out-of-body computer. Data may be transferred in real-time mode or non-real-time. Human body monitoring applications requires real-time data transfer. Monitoring an athlete's physiological data can be collected offline, for processing and analysis purposes, by physicians.

A typical wireless body area network consists of a few compact low-power sensing devices, control unit and wireless transceivers. The power supply for these components should be compact, lightweight, and long-lasting as well. WBANs consists of compact devices with low volume and fewer opportunities for redundancy. To improve the efficiency of WBAN, it is important to minimize the number of nodes in the network. Adding more devices and path redundancy for solving node failure and network problems cannot be a practical option in WBAN systems. WBANs receive and transmit a large amount of data constantly. Data processing must be hierarchical and efficient. WBANs in a medical area consist of wearable and implantable sensor nodes that can sense biological information from the human body, and transmit it over a short distance wirelessly, to a control device worn on the patient body. The sensor electronics must be miniaturized, low-power, and detect medical signals such as pulse rate, electroencephalography, electrocardiograms, pressure, and temperature. The gathered data from the control devices are then transmitted to remote destinations in a wireless body area network for diagnostic and therapeutic purposes, by including other wireless networks for long-range transmission. If the Wireless WBAN, WWBAN, is part of the telemedicine system, the medical system can alert medical personnel when life-threatening events occur. In addition, patients may benefit from continuous long-term monitoring as a part of a diagnostic procedure. Patients and physician may achieve optimal maintenance of a chronic condition, and can monitor the recovery period after the acute event or surgical procedure. The collected medical data may be a good indicator of cardiac recovery of patients after a heart surgery. Many people are using WBAN devices, such as wearable heart rate monitors, respiration rate monitor, and pedometers, for medical reasons or as part of a fitness regime. WBAN may be attached to cotton shirts to measure respiratory activity, electrocardiograms, electromyograms, and body posture. The recorded data and patient data may be stored and analyzed by employing cloud storage and cloud computing services.

\section{Active T Shape Slot Antennas for Ultra-Wideband IoT and 5G Communication Systems}

A wideband active wearable receiving $\mathrm{T}$ shape slot antenna is shown in Figure 7a. The radiating element is designed to provide the optimal load to the active elements. The antenna electrical parameters were calculated, and tuned, by using Computer Aided Design, CAD, tools. The size of the slot antenna shown in Figure 7 is $116 \mathrm{~mm} \times 70 \mathrm{~mm}$. The radiating element is connected to the LNA via an input matching network. An output matching network connects the amplifier port to the receiver. A DC bias network supplies the required voltages to the amplifiers. The amplifier specifications are given in Table 1. The amplifier complex $\mathrm{S}$ parameters and noise parameters are listed in Table 2. Active slot antenna S11 parameters are shown in Figure 7b. The antenna bandwidth is around $40 \%$ for VSWR better than 2:1. S11 parameters of the T shape wearable slot, on human body, attached to a $1 \mathrm{~mm}$ shirt with 2.2 dielectric constant, are presented in Figure 7c. The active slot antenna S21 parameters, gain, are presented in Figure $7 \mathrm{~d}$. The active computed and measured antenna gain is $18 \pm 2.5 \mathrm{~dB}$ for frequencies from 200 to $580 \mathrm{MHz}$. The active antenna gain is $12.5 \pm 2.5 \mathrm{~dB}$ for 
frequencies from 1 to $3 \mathrm{GHz}$. The active slot antenna noise figure is $0.5 \pm 0.3 \mathrm{~dB}$ for frequencies from $300 \mathrm{MHz}$ to $3.2 \mathrm{GHz}$, as presented in Figure $7 \mathrm{e}$.

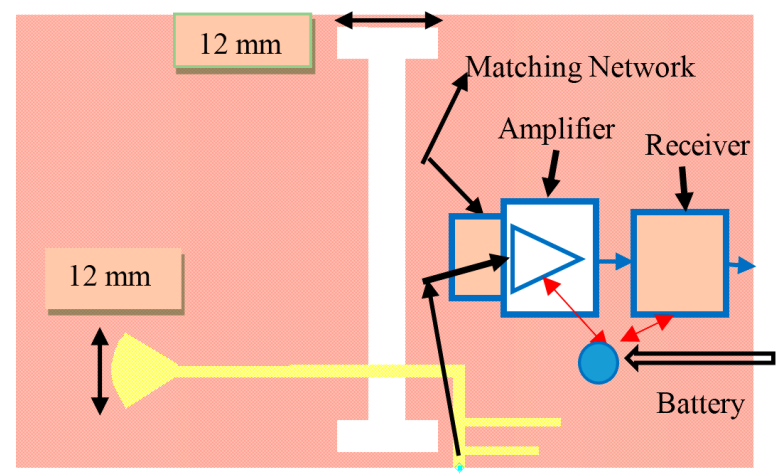

(a)

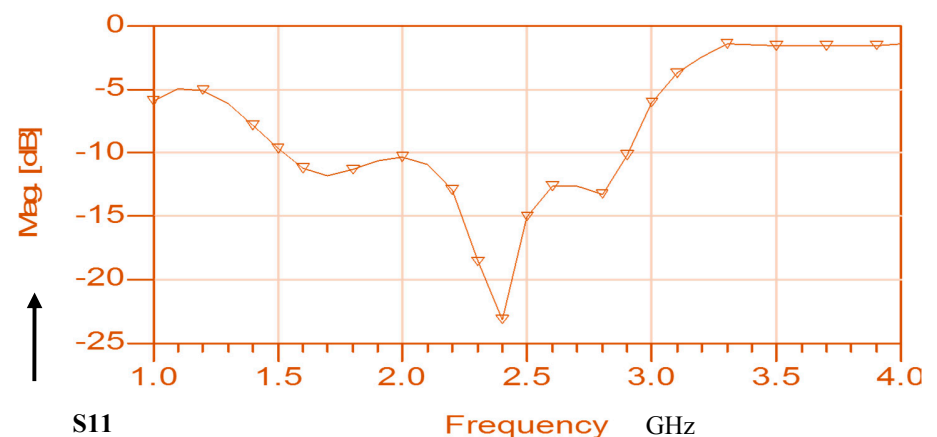

(b)

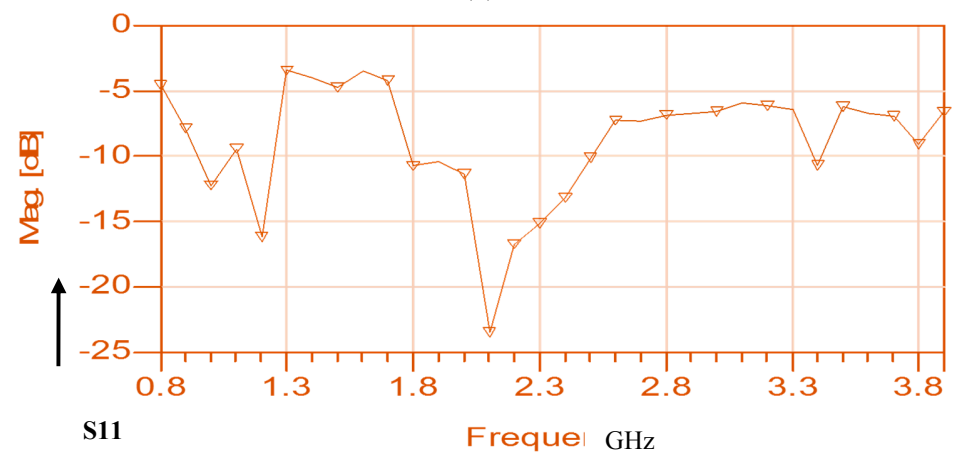

(c)

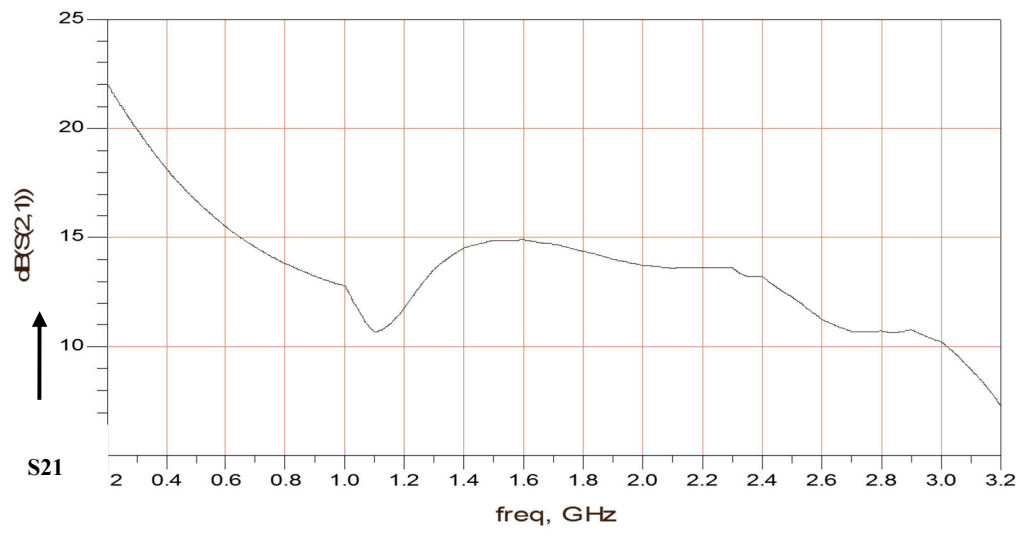

(d)

Figure 7. Cont. 


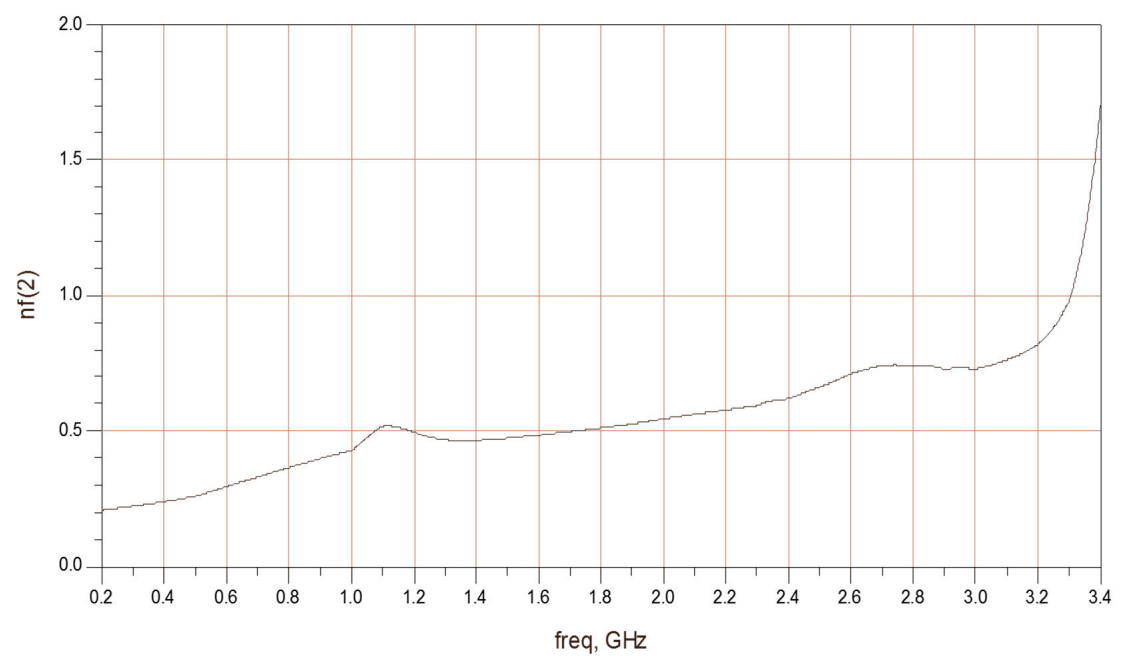

(e)

Figure 7. (a) A wideband active receiving wearable slot antenna; (b) Active T shape slot antenna S11 parameter; (c) S11 of the T shape wearable slot attached to a $1 \mathrm{~mm}$ shirt with $\varepsilon_{r}=2.2$ on human body; (d) Active T shape slot antenna S21 parameter; (e) Active slot antenna noise figure.

A comparison and summary of electrical parameters of the wearable antennas presented in this paper is given in Table 5 .

Table 5. Comparison and summary of electrical parameters of wearable antennas.

\begin{tabular}{ccccc}
\hline Antenna & Frequency (GHz) & VSWR & Gain (dB) & Noise Figure (dB) \\
\hline Loop & 0.45 & $4: 1$ & 0 & - \\
Active receiving loop & $0.35-0.58$ & $2: 1$ & $25 \pm 2.5$ & $0.7 \pm 0.2$ \\
Active Rx. dual polarized antenna & $0.38-0.68$ & $2: 1$ & $25 \pm 2.5$ & $1 \pm 0.5$ \\
Active Tr. dual polarized antenna & $0.38-0.6$ & $3: 1$ & $14 \pm 3$ & - \\
Active transmitting loop antenna & $0.36-0.6$ & $3: 1$ & $13 \pm 3$ & - \\
T shape slot & $1-3$ & $2: 1$ & 3 & - \\
Active Rx. T slot & $0.2-0.58$ & $3: 1$ & $18 \pm 2.5$ & $0.5 \pm 0.3$ \\
\hline
\end{tabular}

\section{Conclusion}

Active wearable BANs may be used in receiving or transmitting channels. In transmitting channels, a power amplifier is connected to the antenna. In receiving channels, a low noise amplifier is connected to the receiving antenna.

Ultra-wideband passive and active printed slot antenna may be employed in wideband wearable IoT and 5G communication systems. The active slot antenna gain and noise figure are summarized in Table 5.

The antennas presented in this paper are low-cost wideband passive and active antennas for receiving and transmitting wearable IoT and 5G communication systems for medical application.

Wearable technology provides a powerful new tool to medical and surgical rehabilitation services. Wearable body area network, WBAN, is emerging as an important option for medical centers and patients. Wearable technology provides a convenient platform that may quantify the long-term context and physiological response of individuals. Wearable technology will support the development of individualized treatment systems with real-time feedback to help promote patients' health. Wearable medical systems and sensors can measure body temperature, heartbeat, blood pressure, sweat rate, perform gait analysis, and other physiological parameters of the person wearing the medical device. 
Gait analysis is a useful tool both in clinical practice and biomechanical research. Gait analysis using wearable sensors provides quantitative and repeatable results over extended time periods with low cost and good portability, showing better prospects and making great progress in recent years. At present, commercialized wearable sensors have been adopted in various applications of gait analysis.

The active transmitting loop antenna and dual polarized antenna output power is around $18 \mathrm{dBm}$. A comparison and summary of electrical parameters of the wearable antennas, presented in this paper, is given in Table 5 .

This paper presents wideband active and tunable printed antennas with high efficiency for commercial and medical applications. The compact tunable antenna bandwidth is around $13 \%$ for a reflection coefficient lower than $-9.5 \mathrm{~dB}$. The tunable antennas gain is around $2 \mathrm{dBi}$. A voltage-controlled diode is used to tune the wearable antenna resonant frequency at different positions on the patient body.

Funding: This research received no external funding.

Conflicts of Interest: The author declares no conflict of interest.

\section{References}

1. Sabban, A. Novel Wearable Antennas for Communication and Medical Systems; Taylor \& Francis Group: Boca Raton, FL, USA, October 2017.

2. Sabban, A. Low Visibility Antennas for Communication Systems; Taylor \& Francis Group: Boca Raton, FL, USA, 2015.

3. Sabban, A. Wideband RF Technologies and Antenna in Microwave Frequencies; Wiley Sons: Hoboken, NJ, USA, July 2016.

4. Sabban, A. New Wideband printed Antennas for Medical Applications. IEEE J. Trans. Antennas Propag. 2013, 61, 84-91. [CrossRef]

5. Sabban, A. Wearable Antenna Measurements in Vicinity of Human Body. Wirel. Eng. Technol. J. 2016, 7, 97-104. [CrossRef]

6. Sabban, A. Small Wearable Meta Materials Antennas for Medical Systems. Appl. Comput. Electromagn. Soc. J. 2016, 31, 434-443.

7. Sabban, A. Microstrip Antenna Arrays. In Microstrip Antennas; Nasimuddin, N., Ed.; InTech: London, UK, 2011; pp. 361-384. ISBN 978-953-307-247-0. Available online: http:/ /www.intechopen.com/articles/show/ title/microstrip-antenna-arrays (accessed on 1 November 2011).

8. Sabban, A. Wideband printed antennas for medical applications. In Proceedings of the APMC 2009 Conference, Singapore, 7-10 December 2009.

9. Sabban, A. Dual Polarized Dipole Wearable Antenna. U.S Patent Number 8203497, 19 June 2012.

10. James, J.R.; Hall, P.S.; Wood, C. Microstrip Antenna Theory and Design; IET: London, UK, 1981.

11. Sabban, A. Microstrip Antennas. In Proceedings of the 11th IEEE Symposium, Tel-Aviv, Israel, October 1979.

12. Sabban, A.; Gupta, K.C. Characterization of Radiation Loss from Microstrip Discontinuities Using a Multiport Network Modeling Approach. IEEE Trans. Microw. Theory Tech. 1991, 39, 705-712. [CrossRef]

13. Sabban, A. A New Wideband Stacked Microstrip Antenna. In Proceedings of the IEEE Antenna and Propagation Symposium, Houston, TX, USA, 23-26 May 1983.

14. Kastner, R.; Heyman, E.; Sabban, A. Spectral Domain Iterative Analysis of Single and Double-Layered Microstrip Antennas Using the Conjugate Gradient Algorithm. IEEE Trans. Antennas Propag. 1988, 36, 1204-1212. [CrossRef]

15. Sabban, A. Wideband Microstrip Antenna Arrays. In Proceedings of the IEEE Antenna and Propagation Symposium MELCOM, Tel-Aviv, Israel, 24-28 May 1981.

16. Chirwa, L.C.; Hammond, P.A.; Roy, S.; Cumming, D.R.S. Electromagnetic Radiation from Ingested Sources in the Human Intestine between $150 \mathrm{MHz}$ and 1.2 GHz. IEEE Trans. Biomed. Eng. 2003, 50, 484-492. [CrossRef] [PubMed]

17. Werber, D.; Schwentner, A.; Biebl, E.M. Investigation of RF transmission properties of human tissues. Adv. Radio Sci. 2006, 4, 357-360. [CrossRef] 
18. Gupta, B.; Sankaralingam, S.; Dhar, S. Development of wearable and implantable antennas in the last decade. In Proceedings of the 2010 10th Mediterranean Microwave Symposium (MMS), Guzelyurt, Cyprus, 25-27 August 2010; pp. 251-267.

19. Thalmann, T.; Popovic, Z.; Notaros, B.M.; Mosig, J.R. Investigation and design of a multi-band wearable antenna. In Proceedings of the 3rd European Conference on Antennas and Propagation, EuCAP 2009, Berlin, Germany, 23-27 March 2009; pp. 462-465.

20. Salonen, P.; Rahmat-Samii, Y.; Kivikoski, M. Wearable antennas in the vicinity of human body. In Proceedings of the IEEE Antennas and Propagation Society International Symposium, Monterey, CA, USA, 20-25 June 2004; Volume 1, pp. 467-470.

21. Kellomaki, T.; Heikkinen, J.; Kivikoski, M. Wearable antennas for FM reception. In Proceedings of the First European Conference on Antennas and Propagation, EuCAP 2006, Nice, France, 6-10 November 2006; pp. 1-6.

22. Lee, Y. Antenna Circuit Design for RFID Applications; Microchip (application note 710c); Microchip Technology Inc.: Chandler, AZ, USA, 2003.

23. Sabban, A. Microstrip Antenna and Antenna Arrays. U.S. Patent US 4,623,893, 18 November 1986.

24. Wheeler, H.A. Small antennas. IEEE Trans. Antennas Propag. 1975, 23, 462-469. [CrossRef]

25. Lin, J.; Itoh, T. Active integrated antennas. IEEE Trans. Microw. Theory Tech. 1994, 42, 2186-2194.

26. Mortazwi, A.; Itoh, T.; Harvey, J. Active Antennas and Quasi-Optical Arrays; John Wiley \& Sons: New York, NY, USA, 1998.

27. Jacobsen, S.; Klemetsen, Ø. Improved detectability in medical microwave radio-thermometers as obtained by active antennas. IEEE Trans. Biomed. Eng. 2008, 55, 2778-2785. [CrossRef] [PubMed]

28. Jacobsen, S.; Klemetsen, Ø. Active antennas in medical microwave radiometry. Electron. Lett. 2007, 43, 606-608. [CrossRef]

29. Ellingson, S.W.; Simonetti, J.H.; Patterson, C.D. Design and evaluation of an active antenna for a $29-47 \mathrm{MHz}$ radio telescope array. IEEE Trans. Antennas Propag. 2007, 55, 826-831. [CrossRef]

30. Segovia-Vargas, D.; Castro-Galan, D.; Garcia-Munoz, L.E.; Gonzalez-Posadas, V. Broadband active receiving patch with resistive equalization. IEEE Trans. Microw. Theory Tech. 2008, 56, 56-64. [CrossRef]

31. Rizzoli, V.; Costanzo, A.; Spadoni, P. Computer-aided design of ultra-wideband active antennas by means of a new figure of merit. IEEE Microw. Wirel. Compon. Lett. 2008, 18, 290-292. [CrossRef]

32. ADS Momentum Software, Keysightt. Available online: http://www.keysight.com/en/pc-1297113/ advanced-design-system-ads?cc=IL\&lc=eng (accessed on 3 January 2018). 